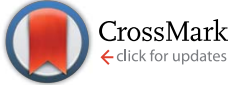

Cite this: J. Mater. Chem. A, 2014, 2 , 16945

\title{
Thermodynamics of thorium substitution in yttrium iron garnet: comparison of experimental and theoretical results
}

\begin{abstract}
X. Guo, ${ }^{a}$ Zs. Rak, ${ }^{\text {b }}$ A. H. Tavakoli, ${ }^{\text {}}$ U. Becker, ${ }^{c}$ R. C. Ewing ${ }^{d}$ and A. Navrotsky ${ }^{\star a}$
The thermodynamic stability of Th-doped yttrium iron garnet $\left(\mathrm{Y}_{3} \mathrm{Fe}_{5} \mathrm{O}_{12}, \mathrm{YIG}\right)$ as a possible actinide-bearing material has been investigated using calorimetric measurements and first-principles electronic-structure calculations. Yttrium iron garnet with thorium substitution ranging from 0.04 to 0.07 atoms per formula unit $\left(\mathrm{Y}_{3-x} \mathrm{Th}_{x} \mathrm{Fe}_{5} \mathrm{O}_{12}, x=0.04-0.07\right)$ was synthesized using a citrate-nitrate combustion method. Hightemperature oxide melt solution calorimetry was used to determine their enthalpy of formation. The thermodynamic analysis demonstrates that, although the substitution enthalpy is slightly endothermic, an entropic driving force for the substitution of Th for $Y$ leads to a near-zero change in the Gibbs free energy. First-principles calculations within the density functional theory (DFT) indicate that the main limiting factors for Th incorporation into the YIG structure are the narrow stability domain of the host YIG and the formation of $\mathrm{ThO}_{2}$ as a secondary phase. Nevertheless, the defect formation energy calculations suggest that by carefully tuning the atomic and electronic chemical potentials, Th can be incorporated into YIG. The thermodynamic results, as a whole, support the possible use of garnet phases as nuclear waste forms; however, this will require careful consideration of the repository conditions.
\end{abstract}

Received 17th July 2014

Accepted 13th August 2014

DOI: $10.1039 / c 4 t a 03683 b$

www.rsc.org/MaterialsA
Radiation tolerance investigations performed on garnet reveal that the average amorphization dose is comparable to that of zircon. $^{22,23,29}$ The radiation response of garnet was found to be topologically constrained and less related to the chemical composition, ${ }^{29}$ implying that garnets as waste forms with various compositions should have similar and predictable radiation tolerance. More importantly, the garnet structure has good chemical stability as shown by the negligible influence of alphadecay damage on the leaching rate in aqueous solution. ${ }^{25}$ This suggests that garnet may be a good candidate for nuclear waste forms. Maintaining chemical integrity is an essential characteristic, especially when the waste form is in contact with subsurface water that may cause release of the radionuclides to the environment. Such scenarios can be encountered, for instance, during the long-term storage of nuclear waste in deep geologic repositories. The long-term stability of garnet was also highlighted by the recent discovery of elbrusite-(Zr), a natural uranium (U) bearing garnet, ${ }^{28}$ containing $\sim 27 \mathrm{wt} \% \mathrm{U}$. It is notable that garnet with a high concentration of $\mathrm{U}\left(\sim 30 \mathrm{wt} \% \mathrm{U}\right.$ to date $\left.{ }^{11,31}\right)$ was also synthesized under laboratory conditions. ${ }^{10,11,19,21,22,26,31}$

The isomorphic capacity of garnet with respect to actinides increases with its iron (Fe) content. ${ }^{10,11,18,26,31}$ The energetics and the incorporation mechanisms of actinides $(\mathrm{U}, \mathrm{Np}$, and $\mathrm{Pu})$ into the structure of $\mathrm{Ca}_{3}\left(\mathrm{Ti}, \mathrm{Zr}, \mathrm{Hf} \text {, and } \mathrm{Sn}_{2}\right)_{2}\left(\mathrm{Fe}_{2} \mathrm{Si}\right) \mathrm{O}_{12}$ garnet series have been investigated using theoretical methods within DFT. ${ }^{30,32-34}$ The results suggest that the magnetic coupling between the actinide $5 \mathrm{f}$ and $\mathrm{Fe} 3 \mathrm{~d}$ states plays a crucial role in the stability of actinides inside the ferric-garnet structure. The 
presence of $\mathrm{Fe}$ is important because it can accommodate the extra charges introduced by the actinides by switching between $2+$ and $3+$ oxidation states. ${ }^{33}$

The relatively wide choice of possible compositions (a variety of actinides and lanthanides) due to three different cation sites and the presence of $\mathrm{Fe}$ as a crucial element in the structure motivated the choice of yttrium iron garnet (YIG) as a host structure for investigating the incorporation mechanisms of actinides/lanthanides and investigating their energetics. The structure of YIG (Fig. 1), $\mathrm{Y}_{3}^{\mathrm{c}} \mathrm{Fe}_{2}^{\mathrm{a}}\left(\mathrm{Fe}^{\mathrm{d}} \mathrm{O}_{4}\right)_{3}$ (Ia3d, $Z=8$ ), has three types of polyhedral cation sites.

The Fe-occupied polyhedra, $\mathrm{FeO}_{4}$ tetrahedra and $\mathrm{FeO}_{6}$ octahedra, are connected alternately by shared corners, and they share edges with $\mathrm{YO}_{8}$ dodecahedra to form a three-dimensional framework. ${ }^{35-37}$ The $24 \mathrm{c}$ eight-coordinated dodecahedral sites can be occupied by large divalent, trivalent, or tetravalent cations, while the 16 a six-coordinated octahedral sites can be occupied by trivalent and tetravalent cations. ${ }^{36,38}$ Thus both sites $\mathrm{c}$ and a can be utilized to incorporate actinides (or lanthanides) depending on the charge balance $;^{36,39}$ however, due to the larger dimension of site $c$, it is expected to be preferred over site a in accommodating larger tetravalent actinide ions.

The incorporation mechanism of $\mathrm{U}$ in YIG is complex, not only because of multiple oxidation states of $U$ (tetravalent, pentavalent, and hexavalent), but also because there are two structural sites (dodecahedral and octahedral) that can potentially accommodate the $U$ cation. Questions concerning the location of $U$ inside the garnet structure were also raised when attempting to assign a proper charge-balanced crystal-chemical formula to natural U-bearing garnets, e.g., in the case of elbrusite-(Zr). ${ }^{28}$ First-principles investigations point to the complexity of incorporation of $U$ in the YIG system. Electronic structure calculations on U-doped YIG indicate that $U$ at the dodecahedral site, in the $4+$ oxidation state, has donated a single electron and at the octahedral site, i.e., in its 5+ oxidation state, has given up two electrons to the neighboring $\mathrm{Fe}^{3+}$ ions. ${ }^{34}$

Previous work on Ce substituted YIG (Ce:YIG) showed that $\mathrm{Ce}$, used as an analogue of U, can be incorporated into YIG at high concentrations, ${ }^{21,26,40-42}$ but Ce can appear in different oxidation states, depending on the amount of substitution.

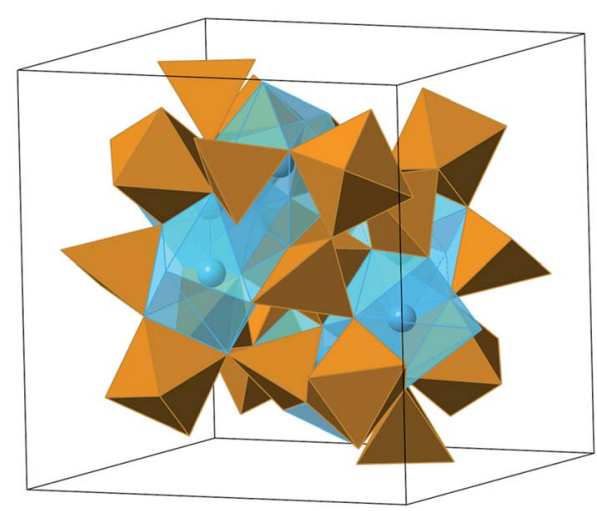

Fig. 1 Schematic figure of the garnet structure. The translucent polyhedra are c sites. The brown octahedra and tetrahedra are a sites and $d$ sites, respectively.
When it is in higher concentration in the garnet system, Ce tends to exist as $\mathrm{Ce}^{4+}$ coupled with the reduced $\mathrm{Fe}^{2+}$ from tetrahedral $\mathrm{Fe}^{3+}$ originally present in YIG. ${ }^{42}$ The energetics of coupled $\mathrm{Ce}^{3+} \mathrm{Fe}^{3+}-\mathrm{Ce}^{4+} \mathrm{Fe}^{2+}$ substitution in Ce:YIG was investigated both calorimetrically and theoretically. The results revealed a competition between energetically unfavorable $\mathrm{Ce}$ oxidation/Fe reduction and a favorable contribution due to strain-energy attenuation. ${ }^{42}$ The present work parallels the previous investigations and deals with the energetics of substitution of Th in YIG through calorimetric measurements and theoretical calculations. Although Th is expected to behave similarly to U, it has only the 4+ oxidation state, in contrast to Ce which may vary between $3+$ and $4+$. Thus, upon substitution of $\mathrm{Th}^{4+}$ for $\mathrm{Y}^{3+}$ in YIG, a portion of the tetrahedral $\mathrm{Fe}^{3+}$ is expected to become reduced to $\mathrm{Fe}^{2+}$ in order to compensate for the higher oxidation state of Th.

\section{Experimental methods}

\section{Sample synthesis}

Substituted yttrium iron garnet samples with a thorium content from 0.04 to 0.07 atoms per formula unit (apfu), $\mathrm{Y}_{3-x} \mathrm{Th}_{x} \mathrm{Fe}_{5} \mathrm{O}_{12}$ $(x=0.04-0.07)$, were synthesized using a citrate-nitrate combustion method. ${ }^{43-45}$ Stoichiometric mixtures of $\mathrm{Y}\left(\mathrm{NO}_{3}\right)_{3} \cdot 6 \mathrm{H}_{2} \mathrm{O}$ (Alfa Aesar, 99.9\%), $\mathrm{Fe}\left(\mathrm{NO}_{3}\right)_{3} \cdot 9 \mathrm{H}_{2} \mathrm{O}$ (SigmaAldrich, 99.99\%), and $\mathrm{Th}\left(\mathrm{NO}_{3}\right)_{4} \cdot 5 \mathrm{H}_{2} \mathrm{O}$ (CERAC, 99\%) were dissolved in an aqueous solution of the citric acid monohydrate (Alfa Aesar, 99.9\%), where the ratio of citric acid to nitrate was kept equal to 0.75 . The obtained solutions were stirred by a magnetic bar to ensure homogeneity, and then were heated to $\sim 90{ }^{\circ} \mathrm{C}$ to evaporate until viscous gels formed. The gels were then heated to $350{ }^{\circ} \mathrm{C}$ in about 2 hours for drying, and subsequently burnt to obtain the brownish-black aggregates of loose powders through a self-propagating combustion. ${ }^{45}$ Finally, the powders were calcined in air at $1300{ }^{\circ} \mathrm{C}$ for 24 hours.

\section{Chemical and structural analysis}

Electron probe microanalysis (EPMA). Chemical composition and homogeneity were determined using a Cameca SX-100 electron microprobe with wavelength-dispersive spectroscopy (WDS) (15 kV accelerating voltage, $10 \mathrm{nA}$ beam current and a spot size of $1 \mu \mathrm{m})$. The obtained powder samples were pelletized, sintered, and then polished prior to analysis. Yttrium aluminum garnet (YAG), hematite $\left(\mathrm{Fe}_{2} \mathrm{O}_{3}\right)$, and thorianite $\left(\mathrm{ThO}_{2}\right)$ were used as analytical standards. At least ten measurements were done for each sample in order to increase the accuracy of the measurements.

Powder X-ray diffraction (XRD). Phases were identified and the purity was determined by X-ray diffraction (XRD) analysis using a Bruker D8 $(\mathrm{Cu} \mathrm{K} \alpha$ radiation, $40 \mathrm{kV}, 30 \mathrm{~mA})$. XRD patterns were obtained from 16 to $80^{\circ} 2 \theta$ with a step size of $0.016^{\circ}$ and a collection time of $2 \mathrm{~s}$ per step.

\section{Calorimetry}

High-temperature drop solution calorimetry was used for the determination of the enthalpies of formation of the garnet 
samples. For each measurement, a $\sim 5 \mathrm{mg}$ pellet of sample was dropped from room temperature into the molten sodium molybdate $\left(3 \mathrm{NaO} \cdot 4 \mathrm{MoO}_{3}\right)$ solvent at $702{ }^{\circ} \mathrm{C}$ in a custom-built Tian-Calvet twin microcalorimeter. ${ }^{46,47}$ The accuracy of the measured data was maximized by making multiple drops (5-10 per composition) of each sample. Oxygen gas was bubbled through the molten solvent at $5 \mathrm{~mL} \mathrm{~min}^{-1}$ to maintain oxidizing conditions, to facilitate dissolution of samples, and to prevent local saturation. In addition, oxygen gas at $51.6 \mathrm{~mL} \mathrm{~min}^{-1}$ was continuously flushed through the calorimeter glassware assembly to maintain a constant gas environment above the solvent and remove any evolved gases. ${ }^{48}$ More details on the equipment, calibration, and experimental method have been described elsewhere. ${ }^{46,47}$

\section{Theoretical methods}

Computational parameters. The experimental results are complemented by electronic structure calculations. The calculations were completed using the projector augmented wave $(\mathrm{PAW})^{\mathbf{4 9 , 5 0}}$ method within density functional theory (DFT) ${ }^{51,52}$ as implemented in the Vienna $\mathrm{Ab}$ initio Simulation Package (VASP). ${ }^{53-56}$ The exchange-correlation potential was approximated by the generalized gradient approximation (GGA), as parameterized by Perdew, Burke, and Ernzerhof (PBE). ${ }^{57}$ The standard PAW potentials, supplied with the VASP package, were employed in the calculations. The cut-off energy for the plane wave basis was set to $520 \mathrm{eV}$, and the convergence of selfconsistent cycles was assumed when the energy difference between two consecutive cycles was less than $10^{-4} \mathrm{eV}$. All calculations involving the garnet structure used a $3 \times 3 \times 3$ Monkhorst-Pack $k$-point mesh ${ }^{58}$ and a Gaussian smearing of 0.1 $\mathrm{eV}$. The internal structural parameters were relaxed until the Hellmann-Feynman forces on each nuclei were less than $0.02 \mathrm{eV}$ $\AA^{-1}$. The calculations on the Th-containing garnet structures were carried out using the calculated lattice constants of YIG ( $a=12.49 \AA)$. This value is approximately $1 \%$ larger than the experimental one measured at room temperature $(a=12.38 \AA){ }^{59}$

In order to describe the behavior of the localized Fe $3 \mathrm{~d}$ states, we have included the orbital-dependent, Coulomb potential (Hubbard $U$ ) and the exchange parameter $J$ in the calculations within the DFT $+U$ method..$^{60,61}$ The value of the Hubbard $U$ parameter can be estimated from band-structure calculations in the supercell approximation with different $\mathrm{d}$ and $\mathrm{f}$ occupations. ${ }^{\mathbf{2}}$ Here, the $U$ and $J$ parameters were treated as adjustable parameters using the following values: $U\left(\mathrm{Fe}_{\mathrm{d}}\right)=4.8 \mathrm{eV}$ with the corresponding $J\left(\mathrm{Fe}_{\mathrm{d}}\right)=0.5 \mathrm{eV}$. These values are physically reasonable and are within the range of the previous values in the literature. ${ }^{\mathbf{6 3 6 4}}$ The DFT $+U$ method was also employed for $\mathrm{ThO}_{2}$, where the values of $U\left(\mathrm{Th}_{\mathrm{f}}\right)=6.5 \mathrm{eV}$ and $J\left(\mathrm{Th}_{\mathrm{f}}\right)=0.5 \mathrm{eV}$ were applied to the localized $5 f$ states of Th. Even though these states are unoccupied, as pointed out by Cevik and Cagin, ${ }^{65}$ the inclusion of the orbital dependent potential is essential to reproduce experimental cell parameters, bulk modulus, and electronic properties of $\mathrm{ThO}_{2}$. It was also found that the thermodynamic properties investigated in the present work are reproduced in better agreement with experiment when the DFT $+U$ method is applied to $\mathrm{ThO}_{2}$.

\section{First-principle thermodynamics}

The thermodynamic stability of Th in the YIG structure was studied using first-principles-based equilibrium thermodynamics in which experimental enthalpies of formation are combined with calculated DFT energies. The creation of a defect in a crystalline solid can be regarded as a process through which atoms and electrons are exchanged between the host material and chemical reservoirs. Therefore, the energy required to create a defect $D$ in charge state q can be calculated as: ${ }^{66}$

$$
\Delta H_{\mathrm{f}}\left(D^{\mathrm{q}}\right)=E\left(D^{\mathrm{q}}\right)-E_{0}+\sum_{\mathrm{i}} n_{\mathrm{i}}\left(\mu_{\mathrm{i}}+E_{\mathrm{i}}\right)+q\left(E_{\mathrm{F}}+E_{\mathrm{VBM}}\right)
$$

In eqn (1), $E\left(D^{\mathrm{q}}\right)$ and $E_{0}$ are the total energies of the defectcontaining and defect-free solids. The last two terms in eqn (1) represent the change in energy due to the exchange of atoms and electrons between the host compound and the chemical reservoirs: $\mu_{\mathrm{i}}$ represents the atomic chemical potential of species $i(i=\mathrm{Y}, \mathrm{Fe}, \mathrm{O}$, and $\mathrm{Th})$ referenced to the energy $E_{\mathrm{i}}$ of the elemental solid/gas and $n_{\mathrm{i}}$ is the number of atoms added to $\left(n_{\mathrm{i}}<0\right)$ or removed from $\left(n_{\mathrm{i}}>0\right)$ the supercell. $E_{\mathrm{F}}$ is the electron chemical potential (i.e., Fermi energy) referenced to the energy of the valence band maximum (VBM), $E_{\mathrm{VBM}}$, and $q$ represents the charge state of the defect (i.e., the number of electrons exchanged with the electron reservoir). In principle, by adjusting the atomic chemical potentials and by tuning the Fermi energy, one can control the defect formation energy and consequently the solubility of the dopant in the host material.

Under thermodynamic equilibrium, the achievable values of the atomic chemical potentials are limited by the following conditions:

(i) In order to maintain a stable YIG host the $\mu_{\mathrm{i}}$ 's must satisfy

$$
3 \mu_{\mathrm{Y}}+5 \mu_{\mathrm{Fe}}+12 \mu_{\mathrm{O}}=\Delta H\left(\mathrm{Y}_{3} \mathrm{Fe}_{5} \mathrm{O}_{12}\right)=\Delta H(\mathrm{YIG})
$$

where $\Delta H(\mathrm{YIG})$ is the formation enthalpy of YIG.

(ii) Because the atomic chemical potentials are referenced to the energies of elemental solids/gases, to avoid elemental precipitations, the chemical potentials are bound by

$$
\mu_{\mathrm{Y}} \leq 0, \mu_{\mathrm{Fe}} \leq 0, \mu_{\mathrm{O}} \leq 0, \text { and } \mu_{\mathrm{Th}} \leq 0
$$

(iii) In order to avoid formation of competing phases, such as iron oxides (Wüstite, hematite, and magnetite) and yttrium oxide, the following conditions must apply:

$$
n \mu_{\mathrm{Fe}}+m \mu_{\mathrm{O}} \leq \Delta H\left(\mathrm{Fe}_{n} \mathrm{O}_{m}\right)
$$

where

$$
\begin{gathered}
(n, m)=(1,1),(2,3), \text { and }(3,4) \\
2 \mu_{\mathrm{Y}}+3 \mu_{\mathrm{O}} \leq \Delta H\left(\mathrm{Y}_{2} \mathrm{O}_{3}\right)
\end{gathered}
$$

(iv) An additional constraint on the chemical potentials is posed by the requirement that the formation of thorium dioxide $\left(\mathrm{ThO}_{2}\right)$ as a secondary phase is avoided: 


$$
\mu_{\mathrm{Th}}+2 \mu_{\mathrm{O}} \leq \Delta H\left(\mathrm{ThO}_{2}\right)
$$

The elemental reference energies, $E_{\mathrm{i}}$, required for eqn (1), are evaluated by combining experimental formation enthalpies listed in thermochemistry tables ${ }^{67}$ with calculated DFT energies: ${ }^{68-73}$

$$
\Delta H^{\exp }\left(A_{n} B_{m} \cdots\right)=E^{\mathrm{DFT}}\left(A_{n} B_{m} \cdots\right)-n E_{\mathrm{A}}-m E_{\mathrm{B}}-\ldots
$$

Using the DFT energies of the binary oxides that can be formed with $\mathrm{Y}, \mathrm{Fe}$, and Th, and for which the experimental formation enthalpies are available, eqn (7) becomes an over determined system of equations that can be solved for the elemental energies using the least-squares method. This has the advantage that the elemental energies are evaluated without performing DFT calculations on the elemental phases. Therefore, this approach avoids the comparison between DFT energies of chemically and physically dissimilar systems (e.g., insulating or semiconducting oxides and elemental metals or gases) where the DFT error cancellation is known to be incomplete. ${ }^{74}$ The elemental energies, $E_{\mathrm{i}}$, can be inserted back in eqn (7) in order to evaluate the theoretical enthalpies of formation of the various compounds used in this investigation. Because the elemental energies are calculated using the standard formation enthalpies, this method extends the $0 \mathrm{~K}$ DFT results to finite temperatures and pressures. More precisely, the calculated chemical potentials and formation enthalpies correspond to values at standard conditions $\left(25^{\circ} \mathrm{C}\right.$ at $\left.0.1 \mathrm{MPa}\right)$.

\section{Results and data analysis}

\section{Structure and composition}

The obtained Th:YIG samples were first characterized by using XRD and EMPA to ensure the phase purity and homogeneity. For samples with Th content less than $0.07 \mathrm{apfu}$, no additional phases are evidenced in the XRD patterns (Fig. 2).

However, a minor amount of $\mathrm{ThO}_{2}$ impurity (less than $1 \%$ in area of the total sample area) was observed in the backscattered electron image. Chemical compositions of the main phase Th:YIG were measured by WDS against the standards on the basis of oxygen stoichiometry. The measured contents of $\mathrm{Y}, \mathrm{Fe}$, and $\mathrm{Th}$ are in stoichiometric values within analytical uncertainty (Table 1). The chemical formulae normalized to 12 oxygen atoms per formula are $\mathrm{YIG},\left(\mathrm{Y}_{2.95} \mathrm{Fe}_{0.05}\right)^{\mathrm{VIII}} \mathrm{Fe}_{5} \mathrm{O}_{12} ; 0.04 \mathrm{Th}$ :YIG,

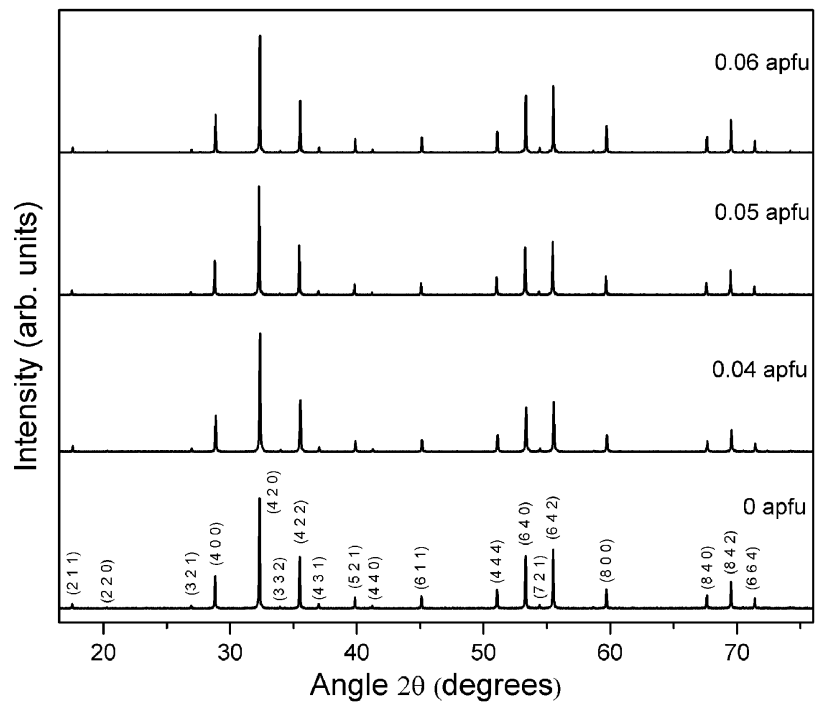

Fig. 2 Powder X-ray diffraction patterns of Th substituted yttrium iron garnet. All of the patterns are indexed based on the cubic yttrium iron garnet structure, JCPDS no. 77-1998.

$\left(\mathrm{Y}_{2.90} \mathrm{Th}_{0.04} \mathrm{Fe}_{0.05}\right)^{\mathrm{VIII}} \mathrm{Fe}_{5} \mathrm{O}_{12} ; \quad$ 0.05Th:YIG, $\quad\left(\mathrm{Y}_{2.90} \mathrm{Th}_{0.05} \mathrm{Fe}_{0.04}\right)-$ ${ }^{\text {VIII }} \mathrm{Fe}_{5} \mathrm{O}_{12}$; and 0.06Th:YIG, $\left(\mathrm{Y}_{2.88} \mathrm{Th}_{0.06} \mathrm{Fe}_{0.05}\right)^{\mathrm{VIII}} \mathrm{Fe}_{5} \mathrm{O}_{12}$.

\section{Thermodynamic analysis using experimental calorimetric} data

The enthalpy of drop solution, $\Delta H_{\mathrm{ds}}$, was directly obtained from the calorimetric measurements. The measured $\Delta H_{\mathrm{ds}}$ values represent the sum of three heat effects: the heat content of the sample from room temperature (RT) to $702{ }^{\circ} \mathrm{C}$, the dissolution enthalpy of the sample in the melt solvent, and the additional enthalpy term from the oxidation of $\mathrm{Fe}^{2+}$ to $\mathrm{Fe}^{3+}$ inside the calorimeter. ${ }^{75,76}$ The obtained $\Delta H_{\mathrm{ds}}$ values, listed in Table 2, combined with the other known enthalpies of drop solution of oxides, were used to derive the enthalpies of formation, $\Delta H_{\mathrm{f}, \mathrm{ox}}$, of the samples relative to binary oxides $\mathrm{Y}_{2} \mathrm{O}_{3}, \mathrm{Fe}_{2} \mathrm{O}_{3}$, and $\mathrm{ThO}_{2}$ through the thermochemical cycles given in Table $3 \mathrm{a}$ and $\mathrm{b}$. The enthalpy of formation of pure YIG from oxides was calculated to be $-55.8 \pm 3.2 \mathrm{~kJ} \mathrm{~mol}^{-1}$, and those of $0.04,0.05$, and $0.06 \mathrm{Th}: \mathrm{YIG}$ are $-52.9 \pm 2.7,-55.7 \pm 2.7$, and $-52.3 \pm 2.9 \mathrm{~kJ} \mathrm{~mol}^{-1}$, respectively. Using the thermochemical cycle given in Table $3 \mathrm{~b}$, the enthalpies of formation are calculated relative to a different

Table 1 Elemental analysis of the synthesized garnet samples analysed by electron microprobe analysis (EMPA) ${ }^{a, b}$

\begin{tabular}{llll}
\hline Sample & Y & Fe & Th \\
\hline YIG & $35.64 \pm 0.56(14.73)^{a}$ & $38.43 \pm 0.36(25.28)$ & - \\
0.04Th:YIG & $34.77 \pm 0.21(14.48)$ & $38.15 \pm 0.39(25.29)$ & $1.23 \pm 0.07(0.20)$ \\
0.05Th:YIG & $34.59 \pm 0.21(14.49)$ & $37.77 \pm 0.38(25.20)$ & $1.56 \pm 0.08(0.25)$ \\
0.06Th:YIG & $34.50 \pm 0.21(14.40)$ & $38.05 \pm 0.39(25.25)$ & $1.78 \pm 0.09(0.29)$
\end{tabular}

${ }^{a}$ wt $\%$ with at\% in parenthesis. Uncertainty is two standard deviations of the mean. ${ }^{b}$ The chemical formulae normalized to 12 oxygen atoms are listed as follows: YIG: $\left(\mathrm{Y}_{2.95} \mathrm{Fe}_{0.05}\right)^{\mathrm{VIII}} \mathrm{Fe}_{5} \mathrm{O}_{12} ; 0.04 \mathrm{Th}: \mathrm{YIG}:\left(\mathrm{Y}_{2.90} \mathrm{Th}_{0.04} \mathrm{Fe}_{0.05}\right)^{\mathrm{VIII}} \mathrm{Fe}_{5} \mathrm{O}_{12} ; 0.05 T h: \mathrm{YIG}:\left(\mathrm{Y}_{2.90} \mathrm{Th}_{0.05} \mathrm{Fe}_{0.04}\right)^{\mathrm{VIII}} \mathrm{Fe}_{5} \mathrm{O}_{12} ; 0.06 \mathrm{Th}: \mathrm{YIG}$ $\left(\mathrm{Y}_{2.88} \mathrm{Th}_{0.06} \mathrm{Fe}_{0.05}\right)^{\mathrm{VIII}} \mathrm{Fe}_{5} \mathrm{O}_{12}$. 
Table 2 Enthalpies of drop solution and enthalpies of formation of $\mathrm{Y}_{3-x} \mathrm{Th}_{x} \mathrm{Fe}_{5} \mathrm{O}_{12}$ from binary oxides and from elements at $25{ }^{\circ} \mathrm{C}$

\begin{tabular}{llllll}
\hline Sample & $\begin{array}{l}\text { Substitution } \\
\text { amount }\end{array}$ & $\Delta H_{\mathrm{ds}}\left(\mathrm{kJ} \mathrm{mol}^{-1}\right)$ & $\Delta H_{\mathrm{f}, \mathrm{ox}}\left(\mathrm{kJ} \mathrm{mol}^{-1}\right)$ & $\Delta H_{\mathrm{f}, \mathrm{ox}}^{\prime}\left(\mathrm{kJ} \mathrm{mol}^{-1}\right)$ & $\Delta H_{\mathrm{f}}^{\circ}\left(\mathrm{kJ} \mathrm{mol}^{-1}\right)$ \\
\hline YIG & 0 & $110.8 \pm 1.8(10)^{42}$ & $-55.8 \pm 3.2$ (ref. 42$)$ & $-55.8 \pm 3.2$ (ref. 42$)$ & $-4979.1 \pm 5.7$ (ref. 42$)$ \\
& & & & & -4979.0 (ref. 77$)$ \\
0.04Th:YIG & 0.04 & $110.1 \pm 0.4(7)$ & $-52.9 \pm 2.7^{a}$ & $-58.8 \pm 2.7^{b}$ & $-4987.3 \pm 5.4^{c}$ \\
0.05Th:YIG & 0.05 & $113.5 \pm 0.5(7)$ & $-55.7 \pm 2.7^{a}$ & $-63.0 \pm 2.7^{b}$ & $-4992.8 \pm 5.4^{c}$ \\
0.06Th:YIG & 0.06 & $110.7 \pm 1.0(5)$ & $-52.3 \pm 2.9^{a}$ & $-61.2 \pm 2.9^{b}$ & $-4992.2 \pm 5.5^{c}$
\end{tabular}

${ }^{a}$ Data taken from $\Delta H_{6}$ in Table 3a. ${ }^{b}$ Data taken from $\Delta H_{7}$ in Table $3 \mathrm{~b} .{ }^{c}$ Data taken from $\Delta H_{5}$ in Table 4.

set of the Fe-containing compounds with consistent oxidation states to the $\mathrm{Fe}^{2+} / \mathrm{Fe}^{3+}$ ratio in the Th:YIG samples. Accordingly, $\Delta H_{\mathrm{f}, \mathrm{ox}}^{\prime}$ of $0.04,0.05$, and 0.06Th:YIG were determined as $-58.8 \pm$ $2.7,-63.0 \pm 2.7$, and $-61.2 \pm 2.9 \mathrm{~kJ} \mathrm{~mol}^{-1}$, respectively. Obviously, values of $\Delta H_{\mathrm{f}, \mathrm{ox}}^{\prime}$ are more negative than those of $\Delta H_{\mathrm{f}, \mathrm{ox}}$. It is understandable because $\Delta H_{\mathrm{f}, \mathrm{ox}}^{\prime}$ are obtained from reactants that is a less stable phase assemblage $\left(\mathrm{Fe}_{0.947} \mathrm{O}+\mathrm{Fe}\right)$ compared to stable phase $\mathrm{Fe}_{2} \mathrm{O}_{3}$ from which $\Delta H_{\mathrm{f} \text {,ox }}$ are derived. It should be noted that $\Delta H_{\mathrm{f}, \mathrm{ox}}$ reflects the long-term thermodynamic stability, while $\Delta H_{\mathrm{f}, \mathrm{ox}}^{\prime}$ characterizes the chemistry and energetics of formation of the crystalline phase from possible oxide species. Furthermore, the enthalpies of formation from elements, $\Delta H_{\mathrm{f}}^{\circ}$, were also derived by using the thermochemical cycle given in Table 4, with the obtained values listed in Table 2.

To evaluate the accuracy of the computational approach in comparison to the calorimetric measurements, the enthalpies of formation $\Delta H_{\mathrm{f}, \mathrm{ox}} \Delta H_{\mathrm{f}, \mathrm{ox}}^{\prime}$, and $\Delta H_{\mathrm{f}}^{\mathrm{o}}$ are calculated using the thermodynamic data derived from first-principles calculations. The DFT energies of YIG, along with the energies of the binary oxides used in eqn (7), are listed in Table 5 . These values can be combined with the thermochemical cycles described in Table $3 \mathrm{a}$ and $\mathrm{b}$ to evaluate the enthalpy of formation of $\mathrm{Y}_{3-x} \mathrm{Th}_{x} \mathrm{Fe}_{5} \mathrm{O}_{12}$ from the most stable binary oxides $\left(\Delta H_{\mathrm{f}, \mathrm{ox}}\right)$ and from $\mathrm{Fe}^{2+}$ and $\mathrm{Fe}^{3+}$ containing oxides $\left(\Delta H_{\mathrm{f}, \mathrm{ox}}^{\prime}\right)$. For the computational model, in the 160-atom supercell, one $\mathrm{Y}$ atom (there are eight $\mathrm{Y}$ atoms in the cell) was substituted by one Th atom, which corresponds to $x=0.125$.

Using the reaction described in Table 3a, the enthalpy of formation of $\mathrm{Y}_{3-x} \mathrm{Th}_{x} \mathrm{Fe}_{5} \mathrm{O}_{12}, x=0.125$ (0.125Th:YIG) from the most stable oxides $\left(\Delta H_{\mathrm{f}, \mathrm{ox}}\right)$ was calculated to be $-39.5 \mathrm{~kJ} \mathrm{~mol}^{-1}$. Employing the cycle described in Table $3 \mathrm{~b}$, together with the DFT energy of FeO, the calculated formation enthalpy $\left(\Delta H_{\mathrm{f}, \mathrm{ox}}^{\prime}\right)$ of 0.125Th:YIG is $-59.6 \mathrm{~kJ} \mathrm{~mol}^{-1}$. Combining the elemental reference energies listed in Table 5 with the thermochemical cycles described in Table 4, the formation enthalpies from elements $\left(\Delta H_{\mathrm{f}}^{\circ}\right)$ can also be calculated: for the pure YIG, this is $-4908.2 \mathrm{~kJ} \mathrm{~mol}^{-1}$, while for 0.125Th:YIG, the value is -4931.6 $\mathrm{kJ} \mathrm{mol}^{-1}$. Considering that the dopant concentration in the theoretical model is considerably higher than that in the experimental samples, the calculated formation enthalpies are

Table 3 Thermochemical cycles for determination of the enthalpies of formation of the garnet compounds from binary oxides

\begin{tabular}{ll}
\hline Reaction & $\Delta H\left(\mathrm{~kJ} \mathrm{~mol}{ }^{-1}\right)$
\end{tabular}

a: Enthalpies of formation of Th:YIG from the most stable binary oxides $\left(\Delta \boldsymbol{H}_{\mathrm{f}, \mathrm{ox}}\right)$ at $25{ }^{\circ} \mathrm{C}$

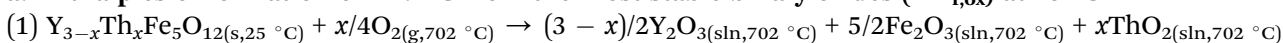

(2) $\left.\left.\mathrm{Y}_{2} \mathrm{O}_{3(\mathrm{~s}, 25}{ }^{\circ} \mathrm{C}\right) \rightarrow \mathrm{Y}_{2} \mathrm{O}_{3(\sin , 702}{ }^{\circ} \mathrm{C}\right)$

(3) $\left.\mathrm{Fe}_{2} \mathrm{O}_{3(\mathrm{~s}, 25}{ }^{\circ} \mathrm{C}\right) \rightarrow \mathrm{Fe}_{2} \mathrm{O}_{3\left(\sin , 702{ }^{\circ} \mathrm{C}\right)}$

(4) $\left.\left.\mathrm{ThO}_{2(\mathrm{~s}, 25}{ }^{\circ} \mathrm{C}\right) \rightarrow \mathrm{ThO}_{2(\sin , 702}{ }^{\circ} \mathrm{C}\right)$

(5) $\mathrm{O}_{2\left(\mathrm{~g}, 25{ }^{\circ} \mathrm{C}\right)} \rightarrow \mathrm{O}_{2\left(\mathrm{~g}, 702{ }^{\circ} \mathrm{C}\right)}$

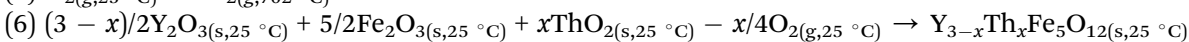

$\Delta H_{\mathrm{f}, \mathrm{ox}}=-\Delta H_{1}+(3-x) / 2 \Delta H_{2}+5 / 2 \Delta H_{3}+x \Delta H_{4}-x / 4 \Delta H_{5}$

$$
\begin{aligned}
& \Delta H_{1}=\Delta H_{\mathrm{ds}} \\
& \Delta H_{2}=-120.7^{a} \pm 0.9^{b}(9)^{c 78} \\
& \Delta H_{3}=94.5 \pm 0.9(8)^{79} \\
& \Delta H_{4}=0.9 \pm 0.5(3)^{80} \\
& \Delta H_{5}=21.8 \text { (ref. 81) } \\
& \Delta H_{6}=\Delta H_{\mathrm{f}, \mathrm{ox}}
\end{aligned}
$$

b: Enthalpies of formation of Th:YIG from binary oxides without change of valence state $\left(\Delta H_{\mathbf{f}, \mathbf{o x}}^{\prime}\right)$ at $25{ }^{\circ} \mathrm{C}$

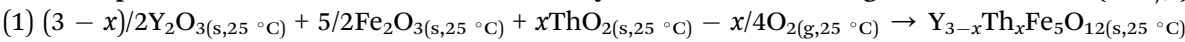

(2) $\left.\left.\mathrm{Fe}_{2} \mathrm{O}_{3(\mathrm{~s}, 25}{ }^{\circ} \mathrm{C}\right) \rightarrow \mathrm{Fe}_{2} \mathrm{O}_{3(\sin , 702}{ }^{\circ} \mathrm{C}\right)$

(3) $\left.\mathrm{Fe}_{0.947} \mathrm{O}_{\left(\mathrm{s}, 25{ }^{\circ} \mathrm{C}\right)}+0.210 \mathrm{O}_{2\left(\mathrm{~g}, 702{ }^{\circ} \mathrm{C}\right)} \rightarrow 0.474 \mathrm{Fe}_{2} \mathrm{O}_{3(\sin , 702}{ }^{\circ} \mathrm{C}\right)$

(4) $\left.\mathrm{Fe}_{(\mathrm{s}, 25}{ }^{\circ} \mathrm{C}\right)+3 / 4 \mathrm{O}_{2\left(\mathrm{~g}, 702{ }^{\circ} \mathrm{C}\right)} \rightarrow 1 / 2 \mathrm{Fe}_{2} \mathrm{O}_{3\left(\sin , 702{ }^{\circ} \mathrm{C}\right)}$

(5) $\left.\left.\left.\left[\mathrm{Fe}_{0.947} \mathrm{O}_{(\mathrm{s}, 25}{ }^{\circ} \mathrm{C}\right)+0.053 \mathrm{Fe}_{(\mathrm{s}, 25}{ }^{\circ} \mathrm{C}\right)\right]+1 / 4 \mathrm{O}_{2\left(\mathrm{~g}, 702{ }^{\circ} \mathrm{C}\right)} \rightarrow 1 / 2 \mathrm{Fe}_{2} \mathrm{O}_{3(\mathrm{~s}, 25}{ }^{\circ} \mathrm{C}\right)$

$\Delta H_{\mathrm{ox}}=-1 / 2 \Delta H_{2}+\Delta H_{3}+0.053 \Delta H_{4}$

(6) $\mathrm{O}_{2\left(\mathrm{~g}, 25{ }^{\circ} \mathrm{C}\right)} \rightarrow \mathrm{O}_{2\left(\mathrm{~g}, 702{ }^{\circ} \mathrm{C}\right)}$

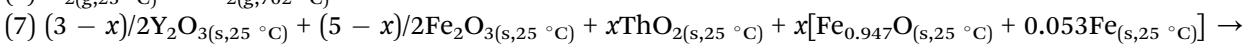

$\left.\mathrm{Y}_{3-x} \mathrm{Th}_{x} \mathrm{Fe}_{5} \mathrm{O}_{12(\mathrm{~s}, 25}{ }^{\circ} \mathrm{C}\right)$

$\Delta H_{\mathrm{f}, \mathrm{ox}}^{\prime}=\Delta H_{1}+x \Delta H_{5}+x / 4 \Delta H_{6}$

${ }^{a}$ Average. ${ }^{b}$ Two standard deviations of the average value. ${ }^{c}$ Number of measurements. ${ }^{d}$ Data taken from $\Delta H_{6}$ in Table 3-a. 
Table 4 Thermochemical cycles for determination of the enthalpies of formation of the garnet compounds from elements at $25^{\circ} \mathrm{C}$

\begin{tabular}{|c|c|}
\hline Reaction & $\Delta H\left(\mathrm{~kJ} \mathrm{~mol}^{-1}\right)$ \\
\hline 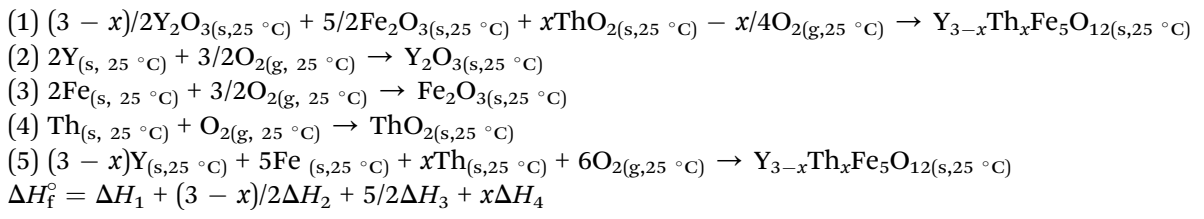 & $\begin{array}{l}\Delta H_{1}=\Delta H_{\mathrm{f}, \mathrm{ox}}{ }^{a} \\
\Delta H_{2}=-1905.3 \pm 2.3 \text { (ref. 82) } \\
\Delta H_{3}=-826.2 \pm 1.3 \text { (ref. 82) } \\
\Delta H_{4}=-1226.4 \pm 3.5(\text { ref. 82) } \\
\Delta H_{\mathrm{f}}^{\circ}\end{array}$ \\
\hline
\end{tabular}

Table 5 The elemental reference energies calculated using eqn (7), the DFT energies of YIG and binary oxides used in eqn (7), along with the experimental and theoretical formation enthalpies of the same compounds. All values are given in $\mathrm{kJ} \mathrm{mol}^{-1}$

\begin{tabular}{|c|c|c|c|c|c|}
\hline Element/compound & $\begin{array}{l}E_{\mathrm{i}}(\text { from } \\
\text { eqn }(7))\end{array}$ & $E^{\mathrm{DFT}}$ & $\Delta H^{\exp }$ & $\begin{array}{l}\Delta H^{\text {theor }} \\
\text { (from eqn (7)) }\end{array}$ & $\begin{array}{l}\Delta\left(\Delta H^{\exp }-\right. \\
\left.\Delta H^{\text {theor }} / \%\right)\end{array}$ \\
\hline $\mathrm{Y}$ & -504.87 & & & & \\
\hline Th & -464.44 & & & & \\
\hline $\mathrm{O}$ & -494.12 & & & & \\
\hline $\mathrm{FeO}$ (cubic) & & -1245.47 & $-263.5^{a}$ & -239.8 & 9.0 \\
\hline $\mathrm{Y}_{2} \mathrm{O}_{3}$ (cubic) & & -4397.15 & $-1904.9^{a}$ & -1905.0 & 0.0 \\
\hline $\mathrm{ThO}_{2}$ (cubic) & & -2802.17 & $-1225.6^{a}$ & -1225.6 & 0.0 \\
\hline $\mathrm{Y}_{3} \mathrm{Fe}_{5} \mathrm{O}_{12}$, YIG (cubic) & & -14910.23 & $-4979.1 \pm 5.7^{b}$ & -4908.2 & 1.4 \\
\hline
\end{tabular}

in reasonably good agreement with the experimental values listed in Table 2. In addition, assuming a linear trend of energy with the Th content in YIG based on DFT calculation, we can extrapolate the thermodynamics of 0.125Th:YIG that could have been obtained by calorimetry. That extrapolated value along with experimental enthalpy of formation values also show a linear relation, plotted in Fig. 3.

\section{Discussion}

The calorimetrically obtained enthalpies of formation of Th:YIG are exothermic (Table 2), indicating that the formation of the garnet phase from a mechanical mixture of its binary oxides is thermodynamically favorable. However, the energetics of substitution should be calculated based on the reaction below that has pure YIG and thoria as reference materials:

$$
\mathrm{Y}_{3} \mathrm{Fe}_{5} \mathrm{O}_{12}+x \mathrm{ThO}_{2} \rightarrow \mathrm{Y}_{3-x} \mathrm{Th}_{x} \mathrm{Fe}_{5} \mathrm{O}_{12}+x / 2 \mathrm{Y}_{2} \mathrm{O}_{3}+x / 4 \mathrm{O}_{2}
$$

The enthalpy change of this reaction (enthalpy of substitution, $\Delta H_{\text {sub }}$ ) can be calculated using the drop solution enthalpies in Table 2. The resulting enthalpies of substitution, $\Delta H_{\text {sub }}$, for 0.04, 0.05, and 0.06Th:YIG are 2.9 $\pm 3.3,0.1 \pm 3.3$, and $3.4 \pm 3.4 \mathrm{~kJ} \mathrm{~mol}^{-1}$, respectively, which are slightly endothermic considering the experimental uncertainty.

In order to estimate the driving force for substitution, namely the Gibbs free energy change $\left(\Delta G_{\text {sub }}=\Delta H_{\text {sub }}-T \Delta S_{\text {sub }}\right)$, we first consider the change of entropy during the substitution,

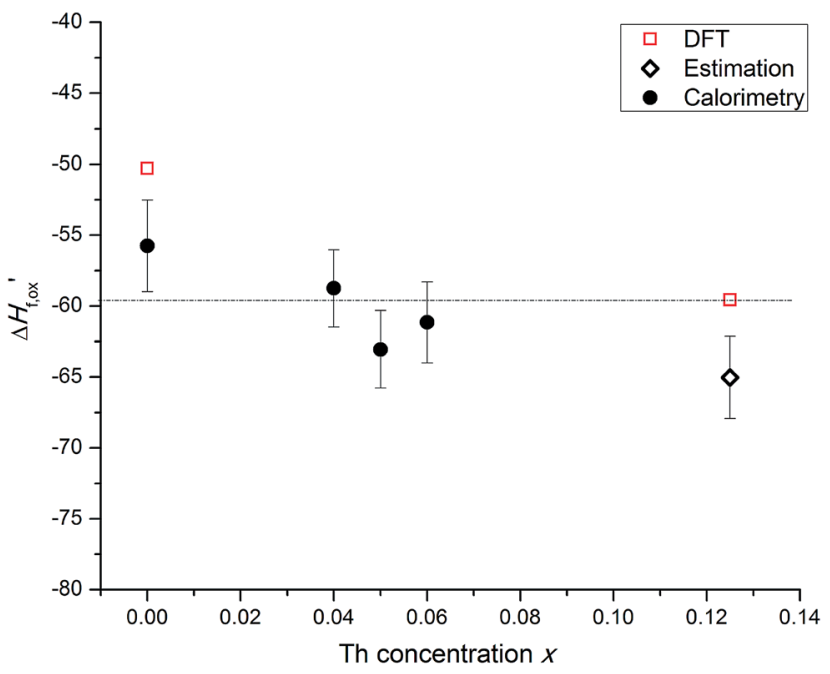

Fig. 3 Enthalpy of formation of YIG and Th:YIG obtained from both calorimetry and DFT-based calculation based on reaction (7) on Table $3 \mathrm{~b}\left(\mathrm{Y}_{2} \mathrm{O}_{3}, \mathrm{Fe}_{2} \mathrm{O}_{3}, \mathrm{FeO}\right.$, and $\mathrm{ThO}_{2}$ are the binary oxides for references). Filled circles: calorimetric enthalpy data; open squares: DFT calculated enthalpy data; open diamonds: estimated values and should be considered to be semiquantitative, and the error bar was given by averaging four experimental data.

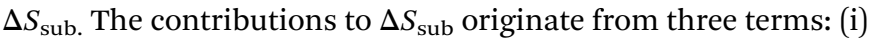
the thermal entropy difference between the reactants and products, (ii) the configurational entropy arising from the 
random distribution of $\mathrm{Th}^{4+}$ with remaining $\mathrm{Y}^{3+}$ in the dodecahedral sites, and reduced $\mathrm{Fe}^{2+}$ with remaining $\mathrm{Fe}^{3+}$ in the tetrahedral sites which has been studied both from computational $^{33}$ and experimental work, ${ }^{42}$ and (iii) evolution of oxygen gas in this reaction. The first part is negligible due to the similar heat capacities of solids. The second part $\Delta S_{\text {conf }}(x$ Th:YIG $)$ is basically estimated by the Boltzmann entropy formula,

$$
\begin{aligned}
\Delta S_{\text {conf }}(x \mathrm{Th}: \mathrm{YIG})= & S_{\text {conf }}\left(\mathrm{Th}^{4+}, \mathrm{Y}^{3+}\right)+S_{\text {conf }}\left(\mathrm{Fe}^{\mathrm{Tet} \_2+}, \mathrm{Fe}^{\mathrm{Tet} \_3+}\right) \\
= & -3 R\left[\frac{3-x}{3} \ln \left(\frac{3-x}{3}\right)+\frac{x}{3} \ln \frac{x}{3}\right] \\
& -3 R\left[\frac{x}{3} \ln \frac{x}{3}+\left(1-\frac{x}{3}\right) \ln \left(1-\frac{x}{3}\right)\right]
\end{aligned}
$$

where the coefficient $x$ is the concentration of Th in a nominal

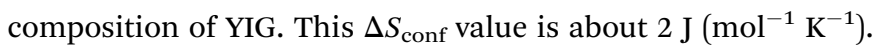
The last part is described as $x / 4 \Delta S_{\mathrm{th}}\left(\mathrm{O}_{2}\right)$. It is generated from the evolution of oxygen, which has $205.147 \mathrm{~J}\left(\mathrm{~mol}^{-1} \mathrm{~K}^{-1}\right)$ per mole of $\mathrm{O}_{2}$ released. ${ }^{81}$ Thus, the entropy of substitution was calculated based on $\Delta S_{\text {sub }}(x$ Th:YIG $)=\Delta S_{\text {conf }}(x$ Th:YIG $)+x / 4 \Delta S_{\text {th }}\left(\mathrm{O}_{2}\right)$, and the Gibbs free energy of substitution can consequently be determined. The values of $\Delta H_{\text {sub }}, \Delta S_{\text {sub }}$, and $\Delta G_{\text {sub }}$ are listed in Table 6. The values of $\Delta G_{\text {sub }}$ are also plotted in Fig. 4, which are almost zero within the standard deviation for the substitution reaction. Thus substitution of $\mathrm{Th}^{4+}$ for $\mathrm{Y}^{3+}$ in the YIG structure has an almost negligible effect on the Gibbs free energy of the system.

Even though there is almost no change in the stability of YIG, the energetics of substitution contains two contributions from the substitution of $\mathrm{Th}^{4+}$ that overall results in a positive enthalpy of Th substitution: the enthalpy of reduction of $\mathrm{Fe}^{3+}$ to $\mathrm{Fe}^{2+}$, and the strain energy from incorporating the larger $\mathrm{Th}^{4+}$ cation. To clearly understand the impact of $\mathrm{Th}^{4+}$ in the dodecahedral site, the reduction effect was estimated by considering the following reaction that has reactants chosen based on the fraction of oxides with different oxidation states the same as those in the sample:

$$
\begin{aligned}
& \mathrm{Y}_{3} \mathrm{Fe}_{5} \mathrm{O}_{12}+x \mathrm{ThO}_{2}+x\left[\mathrm{Fe}_{0.947} \mathrm{O}+0.053 \mathrm{Fe}\right] \rightarrow \\
& \mathrm{Y}_{3-x} \mathrm{Th}_{x} \mathrm{Fe}_{5} \mathrm{O}_{12}+x / 2 \mathrm{Y}_{2} \mathrm{O}_{3}+x / 2 \mathrm{Fe}_{2} \mathrm{O}_{3}
\end{aligned}
$$

The enthalpies of this reaction, $\Delta H_{\text {inco, }}$ can be estimated by subtracting $\Delta H_{7}$ in Table $3 \mathrm{~b}$ from $\Delta H_{\mathrm{f}, \mathrm{ox}}$ of pure YIG, which yield $-3.8 \pm 3.32,-8.3 \pm 3.3$, and $-6.6 \pm 3.4 \mathrm{~kJ} \mathrm{~mol}^{-1}$, for $x=0.04$, 0.05 , and 0.06 , respectively. Thus the net effect of incorporation of $\mathrm{Th}^{4+}$ in dodecahedral sites of YIG is energetically favorable. It also suggests that the substitution of $\mathrm{Th}^{4+}$ for $\mathrm{Y}^{3+}$ is driven enthalpically from better size match of larger $\mathrm{Th}^{4+}$ than $\mathrm{Y}^{3+}$ in the lattice, and entropically from re-distribution of cations in dodecahedral and tetrahedral sites. The amount of $\mathrm{Th}$

Table 6 Enthalpy, entropy, Gibbs free energy of substitution at $25^{\circ} \mathrm{C}$

Sample $\quad \Delta H_{\text {sub }}\left(\mathrm{kJ} \mathrm{mol}^{-1}\right) \quad \Delta S_{\text {sub }}\left(\mathrm{J} \mathrm{mol}^{-1} \mathrm{~K}\right) \quad \Delta G_{\text {sub }}\left(\mathrm{kJ} \mathrm{mol}^{-1}\right)$

0.04Th:YIG

0.05Th:YIG

0.06Th:YIG

\section{$2.9 \pm 3.3$}

$0.1 \pm 3.3$

3.8

$3.4 \pm 3.4$

$$
4.7
$$

5.5
$1.8 \pm 3.3$

$-1.3 \pm 3.3$

$1.8 \pm 3.4$

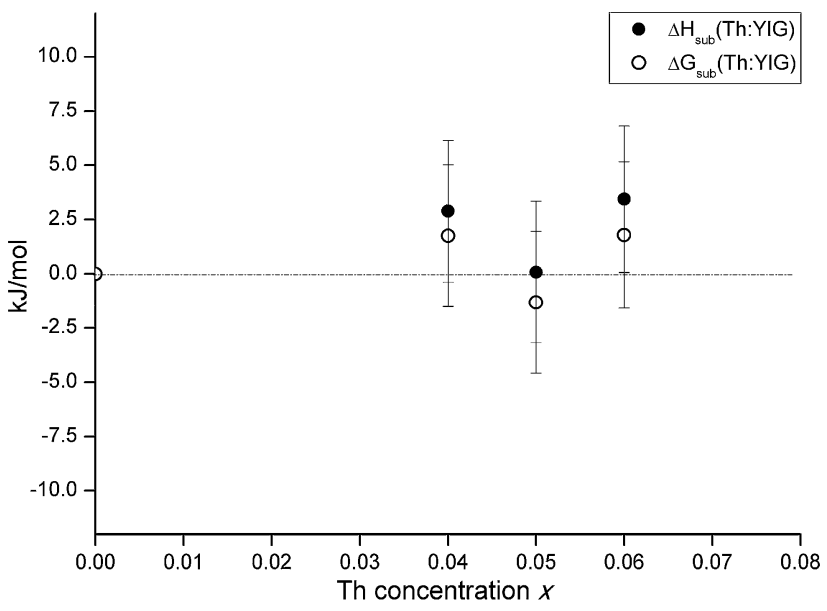

Fig. 4 Enthalpy and Gibbs free energy of substitution in garnets versus thorium concentration, based on the reaction from the most stable binary phases $\left(\mathrm{Y}_{2} \mathrm{O}_{3}, \mathrm{Fe}_{2} \mathrm{O}_{3}\right.$, and $\mathrm{ThO}_{2}$, with release of oxygen). Filled circles: calorimetric enthalpy data; open circles: Gibbs free energy data.

substitution is proportional to the fraction of reduction of $\mathrm{Fe}^{3+}$ to $\mathrm{Fe}^{2+}$, which has an endothermic enthalpy of $152.8 \mathrm{~kJ} \mathrm{~mol}^{-1} .^{79}$ This positive reduction enthalpy is compensated by the negative enthalpy from the incorporation effect until the substitution fraction reaches a certain amount, above which the substitution of $\mathrm{Th}^{4+}$ for $\mathrm{Y}^{3+}$ is energetically hindered due to the dominant enthalpic effect of the reduction.

To bring further insight into the stability of Th in the YIG structure and to determine the thermodynamic limits of Th incorporation, formation energies of substitutional Th are calculated using the chemical potentials defined by conditions (i)-(iv) [eqn (2)-(6)]. To determine the most stable location of Th in the YIG structure, three types of substitutional defects are investigated, where Th is substituting for $\mathrm{Y}$, octahedral $\mathrm{Fe}$, and tetrahedral Fe.

To evaluate the formation energies of the defects, the allowed values of the chemical potentials have to be established. The enthalpy of formation of YIG, as derived from our quantum-mechanical calculations, is $\Delta H(\mathrm{YIG})=4908.19 \mathrm{~kJ}$ $\mathrm{mol}^{-1}$; therefore, according to eqn (2), in order to maintain a stable host, the chemical potentials must satisfy $3 \mu_{\mathrm{y}}+5 \mu_{\mathrm{Fe}}+$ $12 \mu_{\mathrm{O}}=4908.19 \mathrm{~kJ} \mathrm{~mol}^{-1}$. The upper limit for the Fe chemical potential, $\mu_{\mathrm{Fe}}$ can be established as a function of $\mu_{\mathrm{O}}$ using the conditions described by eqn (4): $\mu_{\mathrm{Fe}} \leq-239.76-\mu_{\mathrm{O}}, \mu_{\mathrm{Fe}} \leq$ $-400.07-3 / 2 \mu_{\mathrm{O}}$, and $\mu_{\mathrm{Fe}} \leq-377.33-4 / 3 \mu_{\mathrm{O}}$ to avoid formation of $\mathrm{FeO}, \mathrm{Fe}_{2} \mathrm{O}_{3}$, and $\mathrm{Fe}_{3} \mathrm{O}_{4}$, respectively. Combining these conditions with the requirement to maintain a stable YIG host, the lower limit for the $\mathrm{Y}$ chemical potential as a function of $\mu_{\mathrm{O}}$ is set by: $\mu_{\mathrm{y}} \geq-1236.46-7 / 3 \mu_{\mathrm{O}}, \mu_{\mathrm{y}} \geq-969.28-3 / 2 \mu_{\mathrm{O}}$, and $\mu_{\mathrm{y}} \geq$ $-1007.18-16 / 9 \mu_{\mathrm{O}}$. An additional constraint is imposed on $\mu_{\mathrm{y}}$ by the requirement to avoid formation of $\mathrm{Y}_{2} \mathrm{O}_{3}$, as expressed in eqn (5): $\mu_{\mathrm{y}} \leq-952.52-3 / 2 \mu_{\mathrm{O}}$. Combining these inequalities with the conditions to avoid precipitation of elemental phases, the limiting values for chemical potentials of $\mathrm{O}$ and $\mathrm{Y}$ can be established as $\mu_{\mathrm{O}}^{\min }=-196.78 \mathrm{~kJ} \mathrm{~mol}^{-1}$, with the corresponding $\mu_{\mathrm{y}}^{\max }=-675.35 \mathrm{~kJ} \mathrm{~mol}^{-1}$. The highest achievable value of the $\mathrm{O}$ 
chemical potential, according to eqn (3), is $\mu_{\mathrm{O}}^{\max }=0$, and the corresponding $\mu_{\mathrm{y}}^{\min }=-969.28 \mathrm{~kJ} \mathrm{~mol}^{-1}$. This analysis can be carried on to determine the limits of the Fe chemical potential as well. Combining the conditions to avoid precipitations of $\mathrm{Y}_{2} \mathrm{O}_{3}$ and iron oxides with eqn (2) the lower limit for $\mu_{\mathrm{Fe}}$ is given by $\mu_{\mathrm{Fe}} \geq-410.13-3 / 2 \mu_{\mathrm{O}}$. Substituting the two extreme values of $\mu_{\mathrm{O}}$ derived above, the Fe chemical potential is limited by $\mu_{\mathrm{Fe}}^{\min }=-410.13 \mathrm{~kJ} \mathrm{~mol}^{-1}$ (at $\mu_{\mathrm{O}}^{\max }=0$ ) and $\mu_{\mathrm{Fe}}^{\max }=-114.96$ $\mathrm{kJ} \mathrm{mol}^{-1}$ (at $\mu_{\mathrm{O}}^{\mathrm{min}}=-196.78 \mathrm{~kJ} \mathrm{~mol}^{-1}$ ).

The most stable location of Th inside the YIG structure can be established by calculating the defect formation energies associated with substitutional Th, within the limits of allowed chemical potentials. The formation energies expressed in eqn (1) are written in terms of $\mathrm{O}$ chemical potential and plotted as a function of $\mu_{\mathrm{O}}$ in Fig. 5. In the case of substitutional Th at the $\mathrm{Y}$ site, for instance, the formation energy of the neutral defect is given by $\Delta H_{\mathrm{f}}\left(\mathrm{Th}_{\mathrm{y}}^{\mathrm{O}}\right)=-186.84+\mu_{\mathrm{y}}-\mu_{\mathrm{Th}}$. For the incorporation to be energetically favorable, $\mu_{\mathrm{y}}$ has to be as low as possible and $\mu_{\mathrm{Th}}$ has to be maximized, while still satisfying the conditions to avoid precipitations of secondary and competing phases. In terms of $\mu_{\mathrm{O}}$, this means that $\mu_{\mathrm{y}}=\max \left(-1236.46-7 / 3 \mu_{\mathrm{O}}\right.$, $\left.-969.28-3 / 2 \mu_{\mathrm{O}},-1007.18-16 / 9 \mu_{\mathrm{O}}\right)$ and $\mu_{\mathrm{Th}}=-1225.55-$ $2 \mu_{\mathrm{O}}$. With these expressions, the formation energy of a neutral Th defect at the Y site, $\Delta H_{\mathrm{f}}\left(\mathrm{Th}_{\mathrm{y}}^{\mathrm{O}}\right)$, is calculated and plotted in Fig. 5 as a function of $\mu_{\mathrm{O}}$, for values of $\mu_{\mathrm{O}}$ between $\mu_{\mathrm{O}}^{\min }=$ $-196.78 \mathrm{~kJ} \mathrm{~mol}^{-1}$ and $\mu_{\mathrm{O}}^{\max }=0$. Fig. 5 also illustrates the defect formation energies of neutral Th occupying octahedral and tetrahedral Fe sites, that are calculated in a similar way starting

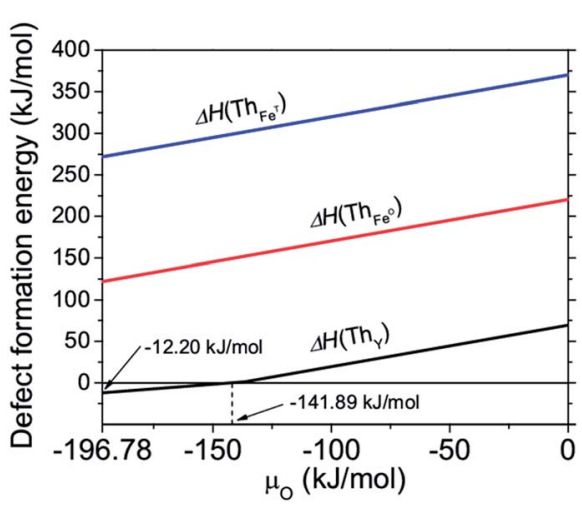

Fig. 5 Defect formation energies as a function of $O$ chemical potential. For all allowed values of $\mu_{\bigcirc}$ the most stable defect is the substitutional $T h$ at the $\mathrm{Y}$ site $\left(T h_{\mathrm{y}}\right)$. from the expressions $\Delta H_{\mathrm{f}}\left(\mathrm{Th}_{\mathrm{Fe}^{\mathrm{O}}}^{\mathrm{O}}\right)=-595.08+\mu_{\mathrm{Fe}}-\mu_{\mathrm{Th}}$ and $\Delta H_{\mathrm{f}}\left(\mathrm{Th}_{\mathrm{Fe}^{\mathrm{T}}}^{\mathrm{O}}\right)=-445.28+\mu_{\mathrm{Fe}}-\mu_{\mathrm{Th}}$. Fig. 5 shows that for all allowed values of $\mu_{\mathrm{O}}$, Th prefers to occupy the dodecahedral site in the YIG structure, substituting for the Y ion.

Moreover, for values of $\mu_{\mathrm{O}} \leq-141.89 \mathrm{~kJ} \mathrm{~mol}^{-1}$, the formation energy $\Delta H_{\mathrm{f}}\left(\mathrm{Th}_{\mathrm{y}}^{\mathrm{O}}\right)$ becomes negative, indicating that the substitution process is exothermic in this range of chemical potential. From Fig. 5, it is apparent that the defect formation energies increase with the $\mathrm{O}$ chemical potential. This is because under O-rich conditions, instead of Th being incorporated into the YIG structure, competing phases $\left(\mathrm{Y}_{2} \mathrm{O}_{3}, \mathrm{Fe}_{2} \mathrm{O}_{3}, \mathrm{Fe}_{3} \mathrm{O}_{4}\right)$ and secondary phases $\left(\mathrm{ThO}_{2}\right)$ tend to precipitate. The lowest formation energy for $\mathrm{Th}_{\mathrm{y}}^{\mathrm{O}}$ occurs at $\mu_{\mathrm{O}}=\mu_{\mathrm{O}}^{\min }=-196.78 \mathrm{~kJ}$ $\mathrm{mol}^{-1}$ and it is $\Delta H_{\mathrm{f}}\left(\mathrm{Th}_{\mathrm{y}}^{\mathrm{O}}\right)=-12.20 \mathrm{~kJ} \mathrm{~mol}^{-1}$. This value is slightly lower than the experimental incorporation enthalpies of $-3.8 \pm 3.3,-8.3 \pm 3.3$, and $-6.6 \pm 3.4 \mathrm{~kJ} \mathrm{~mol}^{-1}$ obtained for 0.04, 0.05, and 0.06Th:YIG, respectively. However, considering the uncertainties in the calculations introduced by the finite size effect as well as the fact that the simulation is performed on a 0.125Th:YIG system, the agreement with the experiment is reasonable. These observations confirm that more reducing conditions, i.e., increasing the $\mathrm{Fe}^{2+} / \mathrm{Fe}^{3+}$ ratio, favor $\mathrm{Th}$ incorporation.

In order to evaluate the effect of doping on Th incorporation energies, calculations have been performed assuming charged defect states. In this case, as indicated by eqn (1), the formation energies also depend on the Fermi level $\left(E_{\mathrm{F}}\right)$, because in order to ionize a defect, electrons must be exchanged with the electron reservoir with energy $E_{\mathrm{F}}$. The formation energies of the charged defects can be calculated using the DFT energies obtained from the charged supercell calculations (values are listed in Table 7) combined with the atomic chemical potentials that produce the most stable defects. The formation energy values are listed in Table 7 and are plotted as a function of $E_{\mathrm{F}}$ in Fig. 6. All defects display similar behavior for the values of $E_{\mathrm{F}}$ within the band gap of YIG: for $E_{\mathrm{F}}$ above the middle of the gap (n-type material) the defects are in the neutral charge state, whereas if $E_{\mathrm{F}}$ is tuned closer to the VBM (p-type material), the defects become positively charged and their formation energies decrease significantly. This suggests that the Th concentration inside the YIG structure can be enhanced by p-type doping of YIG. Furthermore, when $E_{\mathrm{F}}$ is close to the VBM, the formation energy of $\mathrm{Th}_{\mathrm{Fe}}^{\mathrm{O}}$ becomes negative, indicating that in p-type YIG the possibility for Th to occupy octahedral Fe sites cannot be excluded.

Table 7 Calculated DFT energies (in eV) of the defect containing neutral and charged supercells. Defect formation energies (in $\mathrm{kJ} \mathrm{mol}^{-1}$ ) as a function of the atomic chemical potentials and Fermi energy

\begin{tabular}{lllll}
\hline & $Q$ & $\mathrm{Th}_{\mathrm{Y}}$ & $\mathrm{Th}_{\mathrm{Fe}}^{\mathrm{O}}$ & $\mathrm{Th}_{\mathrm{Fe}}^{\mathrm{T}}$ \\
\hline \multirow{2}{*}{$\mathrm{DFT}(\mathrm{eV})$} & 0 & -1237.60 & -1241.76 & -1240.21 \\
& 1 & -1242.38 & -1246.61 & -1245.13 \\
& 2 & -1245.15 & -1249.45 & -1247.94 \\
& 0 & $-186.84+\mu_{\mathrm{Y}}-\mu_{\mathrm{Th}}$ & $-595.08+\mu_{\mathrm{Fe}}-\mu_{\mathrm{Th}}$ & $-445.28+\mu_{\mathrm{Fe}}-\mu_{\mathrm{Th}}$ \\
& 1 & $-396.92+\mu_{\mathrm{Y}}-\mu_{\mathrm{Th}}+E_{\mathrm{F}}$ & $-820.58+\mu_{\mathrm{Fe}}-\mu_{\mathrm{Th}}+E_{\mathrm{F}}$ & $-673.42+\mu_{\mathrm{Fe}}-\mu_{\mathrm{Th}}+E_{\mathrm{F}}$ \\
& 2 & $-406.44+\mu_{\mathrm{Y}}-\mu_{\mathrm{Th}}+2 E_{\mathrm{F}}$ & $-848.67+\mu_{\mathrm{Fe}}-\mu_{\mathrm{Th}}+2 E_{\mathrm{F}}$ & $-694.76+\mu_{\mathrm{Fe}}-\mu_{\mathrm{Th}}+2 E_{\mathrm{F}}$
\end{tabular}




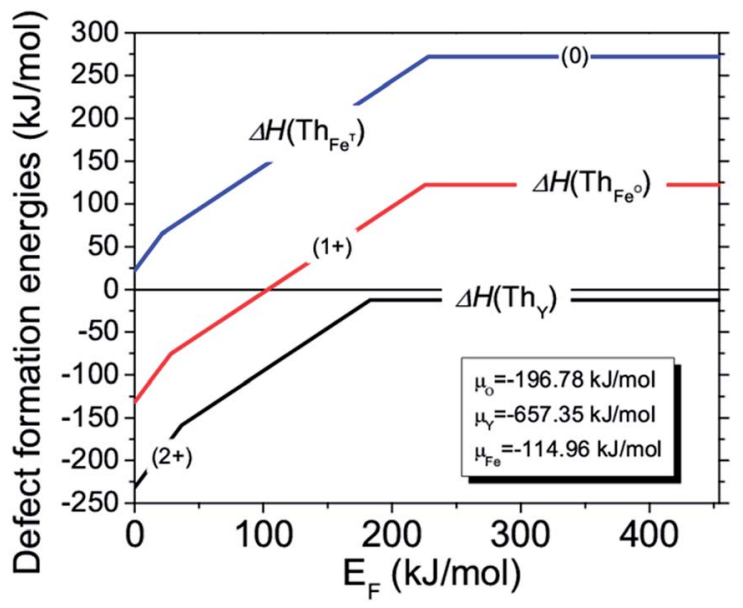

Fig. 6 Formation energies of defects as a function of the Fermi level, calculated using the atomic chemical potentials that produce the most stable defects. The slope of the lines represents the charged state of the defect and the value of $E_{\mathrm{F}}$ where the slope changes represent the charge transition level (or the ionization level).

\section{Conclusions and outlook}

Both calorimetric studies and first principles calculations gave consistent enthalpies of formation of Th substituted YIGs and energies of substitution of Th in YIG. The overall energetic effect of the substitution is near zero, due to the close competition between the favorable incorporation of larger $\mathrm{Th}^{4+}$ cation, and unfavorable reduction of Fe. Entropy has been an influential factor, but not a driving force for the substitution. It is suggested by the DFT calculation that such incorporation can be optimized by p-type doping of YIG. This could be achieved by co-doping YIG with divalent elements such as $\mathrm{Ca}, \mathrm{Mg}$, $\mathrm{Cd}$, or $\mathrm{Zn}$. Preliminary calorimetric studies on Ca, Ce co-doped YIG and $\mathrm{Ca}$, Th co-doped YIG have shown a significant increase in Ce and Th substitution and exhibited more favorable energetics of substitution.

\section{Acknowledgements}

This material is based upon the work supported as part of the Materials Science of Actinides, an Energy Frontier Research Center funded by the U.S. Department of Energy, Office of Science, Office of Basic Energy Sciences under Award Number DESC0001089. The computational work has been performed at the National Energy Research Scientific Computing Center, which is supported by the Office of Science of the U.S. Department of Energy under Contract no. DE-AC02-05CH11231.

\section{Notes and references}

1 W. Lutze and R. C. Ewing, Radioactiv Waste Forms for the Future, Elsevier, Amsterdam, 1988.

2 R. C. Ewing, Proc. Natl. Acad. Sci. U. S. A., 1999, 96, 34323439.

3 R. C. Ewing, Elements, 2006, 2, 331-334.
4 N. P. Laverov, V. I. Velichkin, B. I. Omel'yanenko and, et al., Isolation of Spent Nuclear Materials: Geological and Geochemical Aspects, IFZ RAN, Moscow, 2008.

5 W. J. Weber, A. Navrotsky, S. Stefanovsky, E. R. Vance and E. Vernaz, MRS Bull., 2009, 34, 46-53.

6 W. Sinclair and A. E. Ringwood, Geochem. J., 1981, 15, 229243.

7 T. Ringwood, Am. Sci., 1982, 70, 201-207.

8 S. E. Kesson and A. E. Ringwood, Radioact. Waste Manage., 1983, 4, 159-174.

9 W. J. Weber, R. C. Ewing, C. A. Angell, G. W. Arnold, A. N. Cormack, J. M. Delaye, D. L. Griscom, L. W. Hobbs, A. Navrotsky, D. L. Price, A. M. Stoneham and W. C. Weinberg, J. Mater. Res., 1997, 12, 1946-1978.

10 B. E. Burakov, E. B. Anderson, D. A. Knecht, M. A. Zamoryanskaya, E. E. Strykanova and M. A. Yagovkina, Mater. Res. Soc. Symp. Proc., 1999, 556, 6.

$11 \mathrm{~S}$. V. Yudintsev, M. I. Lapina, A. G. Ptashkin, T. S. Ioudintseva, S. Utsunomiya, L. M. Wang and R. C. Ewing, Mater. Res. Soc. Symp. Proc., 2002, 713, 477-480.

12 R. C. Ewing, W. J. Weber and J. Lian, J. Appl. Phys., 2004, 95, 5949-5971.

13 V. S. Urusov, N. I. Organova, O. V. Karimova, S. V. Yudintsev and S. V. Stefanovskii, Dokl. Earth Sci., 2005, 401, 319325.

14 V. S. Rusakov, V. S. Urusov, R. V. Kovalchuk, Y. K. Kabalov and S. V. Yudincev, Hyperfine Interact., 2005, 164, 99-104.

15 S. Utsunomiya, S. Yudintsev and R. C. Ewing, J. Nucl. Mater., 2005, 336, 251-260.

16 G. R. Lumpkin, Elements, 2006, 2, 365-372.

17 S. V. Yudintsev, S. V. Stefanovsky and R. C. Ewing, in Structural Chemistry of Inorganic Actinide Compounds, ed. S. V. B. Krivovichev, P. C. Burns and I. G. Tananaev, Elsevier, Amsterdam, 2007, pp. 457-490.

18 B. I. Omel'yanenko, T. S. Livshits, S. V. Yudintsev and B. S. Nikonov, Geol. Ore Deposits, 2007, 49, 173-193.

19 B. E. Burakov and E. E. Strykanova, WM'98 Proceedings, Tucson, AZ, United States, 1998.

20 B. E. Burakov, E. B. Anderson, M. A. Zamoryanskaya and M. A. Petrova, Mater. Res. Soc. Symp. Proc., 2000, 608, 4.

21 M. A. Zamoryanskaya and B. E. Burakov, Mater. Res. Soc. Symp. Proc., 2000, 608, 6.

22 S. Utsunomiya, L. M. Wang and R. C. Ewing, Nucl. Instrum. Methods Phys. Res., Sect. B, 2002, 191, 600-605.

23 S. Utsunomiya, L. M. Wang, S. Yudintsev and R. C. Ewing, J. Nucl. Mater., 2002, 303, 177-187.

24 N. P. Laverov, S. V. Yudintsev, T. S. Yudintseva, S. V. Stefanovsky, R. C. Ewing, J. Lian, S. Utsunomiya and L. A. Wang, Geol. Ore Deposits, 2003, 45, 423-451.

25 T. S. Livshits, Geol. Ore Deposits, 2008, 50, 470-481.

26 N. P. Laverov, S. V. Yudintsev, T. S. Livshits, S. V. Stefanovsky, A. N. Lukinykh and R. C. Ewing, Geochem. Int., 2010, 48, 1-14.

27 S. V. Stefanovsky, S. V. Yudintsev and T. S. Livshits, IOP Conf. Ser.: Mater. Sci. Eng., 2010, 9, 12.

28 I. O. Galuskina, E. V. Galuskin, T. Armbruster, B. Lazic, J. Kusz, P. Dzierzanowski, V. M. Gazeev, N. N. Pertsev, 
K. Prusik, A. E. Zadov, A. Winiarski, R. Wrzalik and A. G. Gurbanov, Am. Mineral., 2010, 95, 1172-1181.

29 J. M. Zhang, T. S. Livshits, A. A. Lizin, Q. N. Hu and R. C. Ewing, J. Nucl. Mater., 2010, 407, 137-142.

30 Z. Rak, R. C. Ewing and U. Becker, J. Nucl. Mater., 2013, 436, 1-7.

31 T. S. Youdintseva, Geol. Ore Deposits, 2005, 47, 403-409.

32 Z. Rak, R. C. Ewing and U. Becker, Phys. Rev. B: Condens. Matter Mater. Phys., 2011, 83, 155123.

33 Z. Rak, R. C. Ewing and U. Becker, Phys. Rev. B: Condens. Matter Mater. Phys., 2011, 84, 155128.

34 Z. Rak, R. C. Ewing and U. Becker, J. Phys.: Condens. Matter, 2013, 25, 495502.

35 G. V. Gibbs and J. V. Smith, Am. Mineral., 1965, 50, 20232027.

36 S. Geller, Z. Kristallogr., 1967, 125, 4-5.

37 G. A. Novak and G. V. Gibbs, Am. Mineral., 1971, 56, 791-795.

38 K. R. Whittle, G. R. Lumpkin, F. J. Berry, G. Oates, K. L. Smith, S. Yudintsev and N. J. Zaluzec, J. Solid State Chem., 2007, 180, 785-791.

39 H. Donnerberg, Springer Tracts Mod. Phys., 1999, 151, 165190.

40 S. A. Gramsch and L. R. Morss, J. Alloys Compd., 1994, 207, 432-435.

41 J. S. Kum, S. J. Kim, I. B. Shim and C. S. Kim, Hyperfine Interact., 2004, 156, 169-174.

42 X. F. Guo, A. H. Tavakoli, S. Sutton, R. K. Kukkadapu, L. Qi, A. Lanzirotti, M. Newville, M. Asta and A. Navrotsky, Chem. Mater., 2014, 26, 1133-1143.

43 P. Vaqueiro, M. P. CrosnierLopez and M. A. LopezQuintela, J. Solid State Chem., 1996, 126, 161-168.

44 X. Z. Guo, B. G. Ravi, P. S. Devi, J. C. Hanson, J. Margolies, R. J. Gambino, J. B. Parise and S. Sampath, J. Magn. Magn. Mater., 2005, 295, 145-154.

45 S. H. Vajargah, H. R. M. Hosseini and Z. A. Nemati, J. Alloys Compd., 2007, 430, 339-343.

46 A. Navrotsky, Phys. Chem. Miner., 1977, 2, 89-104.

47 A. Navrotsky, Phys. Chem. Miner., 1997, 24, 222-241.

48 A. Navrotsky, R. P. Rapp, E. Smelik, P. Burnley, S. Circone, L. Chai and K. Bose, Am. Mineral., 1994, 79, 1099-1109.

49 P. E. Blochl, Phys. Rev. B: Condens. Matter Mater. Phys., 1994, 50, 17953-17979.

50 G. Kresse and D. Joubert, Phys. Rev. B: Condens. Matter Mater. Phys., 1999, 59, 1758-1775.

51 P. Hohenberg and W. Kohn, Phys. Rev. B: Solid State, 1964, 136, B864.

52 W. Kohn and L. J. Sham, Phys. Rev., 1965, 140, 1133.

53 G. Kresse and J. Hafner, Phys. Rev. B: Condens. Matter Mater. Phys., 1993, 47, 558-561.

54 G. Kresse and J. Hafner, Phys. Rev. B: Condens. Matter Mater. Phys., 1994, 49, 14251-14269.

55 G. Kresse and J. Furthmuller, Phys. Rev. B: Condens. Matter Mater. Phys., 1996, 54, 11169-11186.

56 G. Kresse and J. Furthmuller, Comput. Mater. Sci., 1996, 6, 15-50.
57 J. P. Perdew, K. Burke and M. Ernzerhof, Phys. Rev. Lett., 1996, 77, 3865-3868.

58 H. J. Monkhorst and J. D. Pack, Phys. Rev. B: Solid State, 1976, 13, 5188-5192.

59 S. Geller and M. A. Gilleo, Acta Crystallogr., 1957, 10, 787.

60 V. I. Anisimov, J. Zaanen and O. K. Andersen, Phys. Rev. B: Condens. Matter Mater. Phys., 1991, 44, 943-954.

61 A. I. Liechtenstein, V. I. Anisimov and J. Zaanen, Phys. Rev. B: Condens. Matter Mater. Phys., 1995, 52, R5467R5470.

62 V. I. Anisimov and O. Gunnarsson, Phys. Rev. B: Condens. Matter Mater. Phys., 1991, 43, 7570-7574.

63 V. I. Anisimov, J. Zaanen and O. K. Andersen, Phys. Rev. B: Condens. Matter Mater. Phys., 1991, 44, 943-954.

64 V. I. Anisimov, I. S. Elfimov, N. Hamada and K. Terakura, Phys. Rev. B: Condens. Matter Mater. Phys., 1996, 54, 43874390.

65 C. Sevik and T. Cagin, Phys. Rev. B: Condens. Matter Mater. Phys., 2009, 80, 014108.

66 S. B. Zhang and J. E. Northrup, Phys. Rev. Lett., 1991, 67, 2339-2342.

67 Materials Thermochemistry, ed. O. Kubaschewski, C. B. Alcock and P. J. Spencer, Pergamon Press, New York, 1993.

68 S. Lany, Phys. Rev. B: Condens. Matter Mater. Phys., 2008, 78, 245207.

69 A. Jain, G. Hautier, S. P. Ong, C. J. Moore, C. C. Fischer, K. A. Persson and G. Ceder, Phys. Rev. B: Condens. Matter Mater. Phys., 2011, 84, 045115.

70 H. B. Guo and A. S. Barnard, J. Mater. Chem., 2011, 21, 11566-11577.

71 V. Stevanovic, S. Lany, X. W. Zhang and A. Zunger, Phys. Rev. B: Condens. Matter Mater. Phys., 2012, 85, 115104.

72 C. J. O'Brien, Z. Rak and D. W. Brenner, J. Phys.: Condens. Matter, 2013, 25, 445008.

73 C. J. O'Brien, Z. Rak and D. W. Brenner, J. Phys. Chem. C, 2014, 118, 5414-5423.

74 R. O. Jones and O. Gunnarsson, Rev. Mod. Phys., 1989, 61, 689-746.

75 A. Navrotsky, D. Dooley, R. Reeder and P. Brady, Am. Mineral., 1999, 84, 1622-1626.

76 K. B. Helean and A. Navrotsky, J. Therm. Anal. Calorim., 2002, 69, 751-771.

77 L. B. Pankratz, Thermodynamic Properties of Carbides, Nitrides, and Other Selected Substances, U.S. Dept. of the Interior, Bureau of Mines, Washington, DC, 1994.

78 W. Q. Chen, T. A. Lee and A. Navrotsky, J. Mater. Res., 2005, 20, 144-150.

79 K. I. Lilova, F. Xu, K. M. Rosso, C. I. Pearce, S. Kamali and A. Navrotsky, Am. Mineral., 2012, 97, 164-175.

80 K. B. Helean, A. Navrotsky, G. R. Lumpkin, M. Colella, J. Lian, R. C. Ewing, B. Ebbinghaus and J. G. Catalano, J. Nucl. Mater., 2003, 320, 231-244.

81 M. W. Chase, J. Phys. Chem. Ref. Data, 1998, 27, I-Ii.

82 R. A. Robie and B. S. Hemingway, U.S. Geol. Surv. Bull., 1995, 2131, 461. 